\title{
Um caso entre a saúde mental e os direitos humanos: as versóes e a vítima
}

I Martinho Braga e Silva |

Resumo: No contexto da primeira condenação do Brasil por violação de direitos humanos, o "Caso Damião Ximenes”, procura-se compreender suas condiçôes de possibilidade, destacando a diversidade de versôes sobre o caso e a construção social de um de seus elementos: a vítima. Uma abordagem antropológica que põe em relevo as formas sociais de classificação é adotada, e documentos midiáticos, governamentais e científicos são objeto de descrição e análise. Saberes jurídicos e médicos são mobilizados para gerar versôes divergentes acerca da morte da vítima, a "apuração dos fatos" sobrepondo-se à "vistoria do corpo", gerando consenso sobre a causa da morte por maus-tratos. A classificação da vítima como uma pessoa com "deficiência”, e não "transtorno mental", contribui para a condenação, a perícia tornando-se fundamental para o desfecho do caso.

> Palavras-chave: saúde mental; deficiência; direitos humanos; violência; vítima.

\author{
1 Doutor em Antropologia \\ Social pelo PPGAS/MN-UFRJ; \\ mestre em Saúde Coletiva \\ pelo IMS-UERJ; especialista \\ em saúde mental pela ENSP- \\ Fiocruz. Professor adjunto \\ do IMS-UERJ. Rio de Janeiro, \\ Brasil. Endereço eletrônico: \\ silmartinho@gmail.com
}

Recebido em: 18/03/2013 Aprovado em: 27/09/2013 
O início do século XXI foi muito relevante para os militantes da luta antimanicomial, dada a promulgação da Lei no 10.216 de 2001 (que redireciona o modelo assistencial em saúde mental, rumo à atenção extra-hospitalar), aplaudida por todos aqueles que mantinham a "utopia de uma sociedade sem manicômios" no campo da Saúde Mental. Logo no ano seguinte, outra importante normativa foi promulgada no Brasil, comemorada pelos que lutavam em defesa dos direitos humanos, o Decreto no 678 de 2002 - que obriga o cumprimento da Convenção Interamericana sobre Direitos Humanos (Convenção IDH) no país -, tornando ainda mais intensa a fiscalização de violações desses direitos no território nacional. O tema deste artigo diz respeito tanto à Saúde Mental quanto aos Direitos Humanos, tendo como foco a análise de um controvertido acontecimento de ordem médica e legal, cujo desenrolar atravessou de modo contundente essas conquistas normativas: o caso Damião Ximenes, no qual o Brasil foi condenado em um tribunal internacional por violação de direitos humanos, em 4 de julho de 2006, devido à morte de um paciente internado em um hospital psiquiátrico, em 4 de outubro de 1999.

Um dos parentes do paciente, convencido de que a morte tinha sido causada por violência perpetrada pelos funcionários do estabelecimento, realizou uma denúncia à Comissão IDH em 22 de novembro de 1999, iniciando, assim, um trâmite no Sistema Interamericano de Direitos Humanos (SIDH), que culminaria no julgamento do caso na Corte Interamericana de Direitos Humanos (Corte IDH). Segundo a sentença da Corte, o Estado brasileiro foi condenado por ter sido considerado responsável pela violação dos direitos consagrados nos artigos $4^{\circ}, 5^{\circ}, 8^{\circ}$ e $25^{\circ}$ da Convenção IDH, respectivamente, os direitos à vida, à integridade pessoal, às garantias judiciais e à proteção judicial (CORTE IDH, Sentença, 2006).

O caso se tornou notório por conta dos precedentes que essa condenação abriu nas jurisprudências nacional e internacional. De um lado, foi a primeira vez que o Brasil foi condenado por violação de direitos humanos na Corte IDH (FRIEDRICH, 2006, p. 28; BORGES, 2009, p. 18), e talvez a primeira condenação do Brasil por violação de direitos humanos em um tribunal 
internacional (BRASIL, 2007); de outro lado, foi a primeira vez que um

país foi condenado por violar os direitos humanos de pessoas acometidas de transtorno mental nesses tribunais internacionais (LIRA; DIAS, 2010, p. 44; ROSATO; CORREIA, 2011, p. 102), ou ao menos no continente americano (BORGES, 2009, p. 27).

O caso também foi considerado relevante no próprio contexto do processo de reforma psiquiátrica brasileira, principalmente por ilustrar "[...] o aprofundamento e radicalização do debate da cidadania nesse período de vigência da lei [10.216 de 2001]" (DELGADO, 2011, p. 119). A Lei 10.216/2001 consolidou a aliança entre saúde mental e direitos humanos no trecho sobre "a proteção e os direitos humanos das pessoas portadoras de transtorno mental", embora após a promulgação da lei os setores da saúde mental e dos direitos humanos, governamentais e não governamentais, dos Poderes Executivo, Legislativo e Judiciário, nem sempre tenham sido aliados. A história desse processo é marcada pelas denúncias acerca das péssimas condições de estadia para os pacientes e de trabalho para os profissionais nos ditos "manicômios", muitos autores destacando justamente a importância da aliança entre os campos da Saúde Mental e dos Direitos Humanos contra a hegemonia do saber psiquiátrico e da instituição asilar nas décadas de 1970 e 1980 (AMARANTE, 1995, p. 90; TENÓRIO, 2002, p. 32; PITTA, 2011, p. 4582).

Dada a importância do caso Damião Ximenes para a compreensão da organização atual do campo da saúde mental em sua relação com os direitos humanos, pretendo abordá-lo neste artigo em dois tópicos. No primeiro, apresentarei as principais versóes sobre o caso, discutindo-as com base principalmente em documentos midiáticos, governamentais e científicos. O objetivo será sublinhar as divergências e as incertezas, mais do que os consensos, sobre certos acontecimentos que se tornaram "fatos" consolidados pelo saber jurídico, como a morte, geralmente atribuída a "maus-tratos". No segundo tópico, procuro apresentar a construção social de um dos principais elementos constitutivos do caso, a vítima. Busco, assim, destacar as categorias médicas e jurídicas através das quais se dissolveu a suspeita de que o estatuto de periculosidade da loucura se aplicava também a Damião Ximenes Lopes, a ponto dele se tornar parte de uma população vulnerável. 


\section{Referencial teórico-metodológico}

O material que subsidia este artigo em parte foi extraído de tese de doutorado em Antropologia Social. O projeto de pesquisa, financiado pelo CNPQ, foi aprovado por Comitê de Ética em Pesquisa, tendo sido utilizados Termos de Consentimento Livre e Esclarecido. A entrada em campo aconteceu através de uma notícia sobre a condenação do Brasil divulgada pela BBC Brasil em 18 de agosto de 2006 (UCHÔA, 2006), enviada a todos os participantes do grupo virtual "Em defesa da reforma" no mesmo mês e ano. O grupo reúne militantes do movimento da luta antimanicomial de todo o país e conta basicamente com três segmentos representativos: usuários, familiares e profissionais de serviços de saúde mental. $\mathrm{Na}$ época em que recebi a notícia, eu fazia parte desse último segmento. O grupo virtual contava, ainda, com a presença de familiares e profissionais envolvidos no caso Damião Ximenes, e a notícia fora enviada por um profissional.

Através do contato com membros do grupo virtual, tornou-se possível realizar o trabalho de campo entre 2006 e 2010. Nesse período, estive na cidade da morte de Damião Ximenes Lopes por cinco meses não sucessivos e realizei entrevistas abertas com representantes de órgãos governamentais e não governamentais envolvidos no caso em outros três municípios também. Ao final, havia recolhido informações de jornais nacionais, da sentença de um tribunal internacional, dos autos de uma ação penal local, do relatório de sindicância de um estabelecimento médico municipal e da carta de um parente da vítima, material que será utilizado ao longo deste artigo. Em menor grau, o conteúdo de entrevistas junto aos envolvidos no caso também será mobilizado durante a análise.

As formas sociais de classificação são estudadas por diferentes autores das ciências sociais (DURKHEIM; MAUSS, 1981; DOUGLAS, 1976) e colaboram para o delineamento das maneiras como ordenamos o mundo onde vivemos e os esquemas de pensamento através dos quais, ao mesmo tempo, distinguimos os elementos do universo simbólico de que fazemos parte e separamos pessoas, grupos, lugares e ideias em categorias. As categorias médicas e jurídicas apontam para alguns desses modos por meio dos quais operaçóes de classificação e ordenação simbólica são efetuadas, sendo que a perícia médica tem um papel histórico nesse processo de integração ou segregação de indivíduos do espaço social (CASTEL, 2000 [1977]). 
Para ser preciso, os saberes médicos, jurídicos, da Saúde Pública e dos

Direitos Humanos encontram-se em confronto no caso, contribuindo para a formulação de diferentes versões, pois a Medicina Legal fundamenta o laudo do cadáver da vítima, o código penal classifica como maus-tratos a causa da morte, a auditoria na casa de repouso acontece tomando como base diretrizes sanitárias sobre o devido funcionamento do estabelecimento e as normativas internacionais, visando à proteção e promoção dos direitos humanos, orientam o parecer do perito da corte internacional. Entretanto, vou adotar o termo "saber médico" para me referir à Medicina Legal e à Saúde Pública durante o texto, bem como "saber jurídico" para a aplicação do código penal nacional e das normativas internacionais, no sentido de facilitar a descrição e a análise do caso, trabalhando com uma polaridade, muito embora a linguagem dos direitos humanos não se encaixe perfeitamente no saber jurídico tradicional. Como a periculosidade e a vulnerabilidade no que diz respeito à classificação da vítima, "saber médico" e "saber jurídico" representam uma polaridade que contribui para dar um contorno à heterogeneidade de versôes sobre o caso, um recurso didático para guiar a leitura.

Como veremos, é o teor pericial dessas atividades que está em jogo, o fato de produzirem laudos, relatórios, pareceres e outros documentos com o poder de mudar o destino de indivíduos, instituições e Estados. Trata-se de uma analogia com outro momento histórico no qual a Medicina e o Direito encontravam-se, ora em conflito, ora em composição: quando a perícia psiquiátrica começou a subsidiar a decisão judicial no sentido de garantir a defesa social no século XIX, enquanto no século XX a proteção e a promoção tanto da saúde pública quanto dos direitos humanos visam garantir a dignidade da pessoa humana.

Assim, este estudo de caso se insere no debate internacional sobre Saúde Mental e Direitos Humanos (BERTOLOTE, 1995; DUDLEY; SILOVE; GALÉ, 2012) e, mais especificamente, na discussão sobre a história das relações entre Psiquiatria e Justiça no Brasil (DELGADO, 1992; CARRARA, 1998). Os tratados internacionais de proteção aos direitos humanos das pessoas acometidas de transtorno (disorder) mental e deficiência (disability) mental serão fundamentais para a compreensão das descrições e análises em curso, bem como da questão do estatuto de periculosidade da loucura e sua relação com a atividade pericial. 


\section{Versōes do caso Damião Ximenes}

A notícia sobre o caso Damião Ximenes, que suscitou o início do trabalho de campo, pode ser um caminho inicial para abordá-lo. À notícia da BBC Brasil (BBC) acrescentarei uma outra, publicada pelo jornal Diário do Nordeste (DN) (CASO..., 2006). A matéria da BBC foi publicada primeiro, no dia 18 de agosto de 2006, sendo dividida em "Caso", "Responsabilidades" e "Decisão Histórica" e mostrando a foto da Corte IDH, de Damião Ximenes Lopes e do Congresso Nacional. A matéria do DN foi publicada no dia seguinte e apresenta apenas uma subdivisão, também nomeada "Caso", mostrando apenas a foto de Damião Ximenes Lopes. Os títulos das notícias são semelhantes - "Brasil é condenado por Corte Interamericana de Direitos Humanos", na BBC, e "Brasil condenado por Corte internacional”, no DN. Assim, através da especificação de seu nome, a Corte é singularizada na matéria da BBC, enquanto é generalizada na matéria do DN (uma dentre outras cortes internacionais).

A matéria da BBC não nomeia o "Caso" de "Caso Damião Ximenes", como a matéria do DN. Desse modo, enquanto o DN não particulariza a corte e o faz com o caso, a $\mathrm{BBC}$ singulariza a corte e não o caso. Além disso, ao se referir às "responsabilidades", a BBC menciona que o "país" terá que indenizar a "família" e que o valor será mais alto do que o inicial, de um salário mínimo. Já o DN explicita o valor monetário, uma "reparação econômica de US\$ 146 mil, equivalentes a R\$ 312 mil”. Enfim, a matéria da BBC tem uma última subdivisão, intitulada "Decisão Histórica", e a expressão "primeira vez" aparece em vários momentos do conjunto da matéria: "a primeira contra o Brasil na Corte Interamericana", "a primeira vez que um caso de abuso de direitos humanos no Brasil é julgado na Corte Interamericana da Organização dos Estados Americanos (OEA)", a "primeira vez" que os "familiares da vítima" "venceram um caso contra o Brasil" e "a primeira vez que [o tribunal] julga a "violação dos direitos de uma pessoa portadora de deficiência mental'”. No DN, esse pioneirismo não merece uma subdivisão, sendo ressaltado apenas em dois momentos, e não em quatro: "Este foi o primeiro caso brasileiro julgado pela Corte" e "A família apresentou o caso, o primeiro envolvendo a questão da saúde mental a ser julgado pela Corte”. 
Essas diferenças entre as informações divulgadas nas notícias parecem depender em parte do público ao qual os jornais se dirigem. Enquanto a BBC visa um público em sua maioria global, o DN dirige-se a uma audiência local. Desse modo, a notícia da BBC esclarece o nome da corte e omite o do caso, enquanto a do DN faz o inverso; a da BBC enfatiza o ineditismo da condenação, e a da $\mathrm{DN}$, o valor monetário da indenização.

Outras notícias foram publicadas sobre o caso, não só na $\mathrm{BBC}$ e no $\mathrm{DN}$, mas também no Correio Brasiliense, na Folha de São Paulo e no jornal O Povo. Contudo, não pretendo me deter nessas outras matérias; gostaria apenas de destacar desde logo algo que pode ser óbvio para muitos, mas que ainda assim deve ser explicitado: essas diferenças nos conteúdos das duas matérias apontam para a inviabilidade delas serem tomadas como correspondentes a supostos fatos sobre o caso. Alguns elementos que compõem o caso foram visibilizados em uma das notícias e não o foram na outra. Até quando trechos são compostos dos mesmos elementos, estes são apresentados com ênfases diferentes.

Além disso, contrastando as informações divulgadas nos jornais com o conteúdo da sentença da Corte IDH (CORTE..., Sentença, 2006), diríamos que a morte da vítima ocorreu em outubro, e não em novembro, de 1999, como afirma a matéria da BBC: "O caso diz respeito à morte do cearense Damião Ximenes, em novembro de 1999 [...]”. Temos, então, divergências entre as versões sobre a data da morte da vítima, entre o "Caso" divulgado pela BBC, o "Caso Damião Ximenes" divulgado pelo DN e o "caso Damião Ximenes Lopes versus Brasil” segundo a sentença da Corte IDH. Desse modo, considero que versões sobre o caso, e não supostos fatos, são divulgadas nas matérias de jornal, em graus variados de convergência e divergência com as informações presentes em outros documentos, tais como a sentença da Corte IDH. Essa consideração vale para qualquer outro documento acerca do caso. É justamente essa diversidade de versões que será aqui enfatizada, não o(s) suposto(s) fato(s) ou verdade(s) sobre o caso.

Podemos, então, retomar os documentos citados, acrescentando informaçôes extraídas de uma carta escrita por um dos parentes de Damião Ximenes, 
publicada em Pereira (2001). Todas essas versões sobre as circunstâncias que cercaram a morte da vítima acentuam os sinais de maus-tratos e tortura, conforme apresentado abaixo:

Tabela Única. Versōes sobre as circunstâncias da morte de Damião Ximenes Lopes

\begin{tabular}{|c|c|}
\hline $\begin{array}{l}\text { Notícia } \\
\text { BBC Brasil } \\
\text { 18/08/2006 }\end{array}$ & $\begin{array}{l}\text { No dia } 1^{\circ} \text { de outubro de } 1999 \text {, Damião foi levado por sua mãe, } \\
\text { Albertina, à Casa de Repouso Guararapes. Ela temia pelas crises do } \\
\text { filho, que também sofria de epilepsia. Na segunda-feira seguinte, } \\
\text { Albertina voltou à clínica, mas teve a notícia de que o paciente } \\
\text { "não estava em condições de receber visitas". Segundo a irmã de } \\
\text { Damião, Irene, a mãe resolveu entrar à força. Lá, encontrou o } \\
\text { filho "amarrado, com as roupas rasgadas, sangrando, coberto } \\
\text { de hematomas e andando com dificuldades", relata Irene. } \\
\text { Caído aos pés da mãe, Damião teria dito: "Polícia, polícia...". }\end{array}$ \\
\hline $\begin{array}{l}\text { Notícia DN } \\
19 / 08 / 2006\end{array}$ & 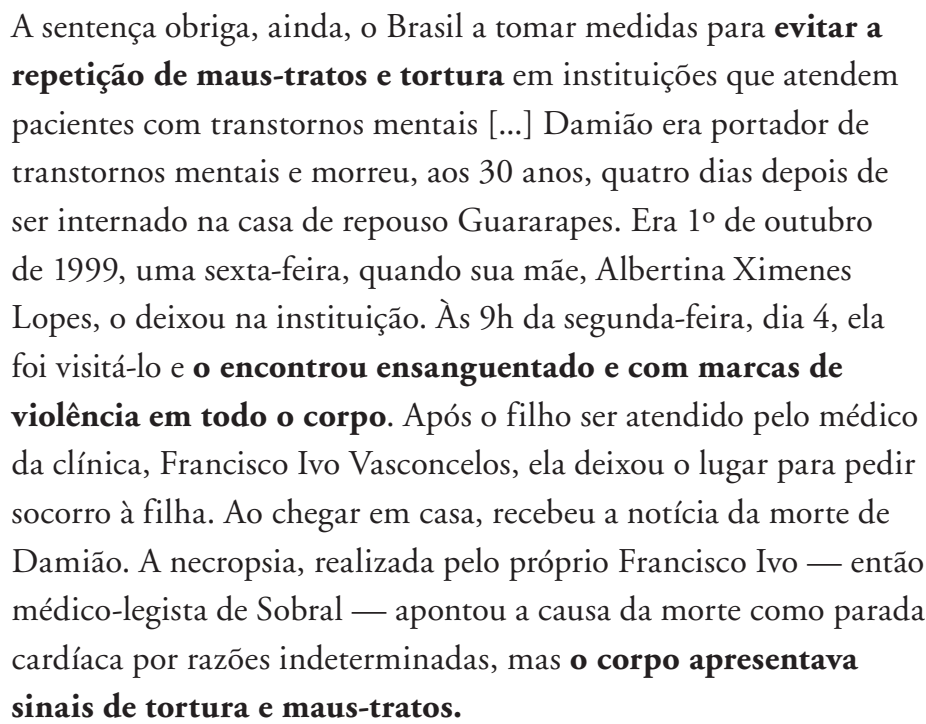 \\
\hline
\end{tabular}




\begin{tabular}{|c|c|}
\hline $\begin{array}{l}\text { Sentença da } \\
\text { Corte IDH } \\
04 / 07 / 2006 \\
\text { (CORTE IDH, } \\
\text { Sentença, 2006: } \\
\text { 34-36) }\end{array}$ & $\begin{array}{l}\text { "VII - FATOS PROVADOS } \\
\text { 112. Efetuado o exame dos elementos probatórios constantes do } \\
\text { expediente deste caso, as manifestações das partes, bem como o } \\
\text { reconhecimento parcial de responsabilidade internacional do Estado, } \\
\text { a Corte considera provados os fatos a seguir relatados." (p. 34) } \\
\text { "B) Maus-tratos e morte do senhor Damião Ximenes Lopes } \\
\text { 112.9. Em } 4 \text { de outubro de 1999, aproximadamente às 9h, } \\
\text { a mãe do senhor Damião Ximenes Lopes chegou à Casa de } \\
\text { Repouso Guararapes para visitá-lo e o encontrou sangrando, } \\
\text { com hematomas, com a roupa rasgada, sujo e cheirando a } \\
\text { excremento, com as mãos amarradas para trás, com dificuldade } \\
\text { para respirar, agonizante e gritando e pedindo socorro à polícia. } \\
\text { Continuava submetido à contenção física que lhe havia sido aplicada } \\
\text { desde a noite anterior, já apresentava escoriações e feridas e pôde } \\
\text { caminhar sem a adequada supervisão. Posteriormente, um auxiliar de } \\
\text { enfermagem o deitou em uma cama, da qual caiu. Então o deitaram } \\
\text { num colchonete no chão." (p.35-36) } \\
\text { [Cf. declaração de Carlos Alberto Rodrigues dos Santos prestada } \\
\text { perante a Terceira Vara da Comarca de Sobral em } 24 \text { de abril de } \\
\text { 2000, nota } 41 \text { supra; declaração de André Tavares do Nascimento } \\
\text { prestada na Delegacia Regional de Sobral em } 26 \text { de novembro de } \\
\text { 1999 (expediente de anexos à demanda, anexo } 29 \text {, folha 180); e } \\
\text { declaração de Albertina Viana Lopes prestada na Delegacia } \\
\text { Regional de Sobral em } 7 \text { de dezembro de 1999 (expediente de } \\
\text { anexos à demanda, anexo } 32 \text {, folhas } 213 \text { e } 214 \text { ).] [nota de rodapé] }\end{array}$ \\
\hline $\begin{array}{l}\text { Carta } \\
\text { s/d } \\
\text { (PEREIRA, } \\
\text { 2001: 131) }\end{array}$ & $\begin{array}{l}\text { Nossa mãe, por receio que ele entrasse em crise, na tarde de sexta- } \\
\text { feira, primeiro de outubro de } 1999 \text {, levou-o ao hospital acima } \\
\text { mencionado e o deixou internado para receber cuidados médicos. } \\
\text { Na segunda-feira pela manhã, quando ela voltou para fazer visita, } \\
\text { encontrou Damião quase morto. Ele havia sido impiedosamente } \\
\text { espancado, estava com as roupas sujas e rasgadas, as mãos } \\
\text { amarradas para trás e seu corpo coberto de sangue. Cheirava } \\
\text { a sangue coagulado, a fezes e a urina. Ele ainda conseguiu } \\
\text { falar, e numa expressão de pedido de socorro, disse: "polícia... } \\
\text { polícia... polícia...". }\end{array}$ \\
\hline
\end{tabular}



(Brasil, 2009), também diz respeito a "maus-tratos", conforme previsto no artigo $136^{\circ}$ do Código Penal Brasileiro. Já a sentença da Corte IDH fala de "violação de direitos humanos", sendo "maus-tratos" um componente da violação, "fato provado" segundo o documento (CORTE IDH, Sentença, 2006). Finalmente, a carta da irmã da vítima também coloca em relevo a versão da causa da morte como tendo sido devida a maus-tratos, além de descrever a casa de repouso como uma "casa de tortura" e acusar a equipe de funcionários do estabelecimento de "homicídio" (PEREIRA, 2001, p. 132).

Para a irmã da vítima, a morte foi resultado de um "espancamento" por parte da equipe de funcionários da clínica psiquiátrica (PEREIRA, 2001, p. 132). Além da descrição da cena em que Damião aparece com ferimentos, vista pela mãe da vítima, na carta é relatado o que a mãe teria ouvido de uma das funcionárias do hospital: "Uma faxineira do hospital contou para mamãe que presenciou tudo; os autores da violência foram os auxiliares de enfermagem e os monitores de pátio, que teoricamente são contratados para apartar brigas, mas não possuem preparo para isso." (PEREIRA, 2001, p. 131, grifo meu).

Enfim, na ação penal local e na sentença do tribunal internacional, a versão segundo a qual a morte foi devida a "maus-tratos" e "tortura" é acentuada, bem como nas notícias nos jornais $\mathrm{BBC}$ e $\mathrm{DN}$ e na carta da irmã da vítima. A tortura, inclusive, é apontada como uma das condições de possibilidade da própria emergência dos direitos humanos na sociedade ocidental, pois a leitura de relatos de tortura teria sido a base de um sentimento compartilhado fundamental para essa moralidade emergente: a empatia (HUNT, 2009, p. 25; 32).

Entretanto, consultando os resultados dos dois laudos médicos de causa da morte, ambos realizados no mesmo dia do óbito e incluídos no primeiro dos quatro volumes dos autos da ação penal (BRASIL, 2009), diríamos que não há consenso sobre a causa da morte. A primeira perícia do corpo, realizada pelo mesmo médico que atendeu a vítima, aponta como causa "parada cardiorrespiratória"; a segunda, realizada por dois médicos-legistas do IML de Fortaleza-CE, diz: "inferimos tratar-se de morte real de causa indeterminada”. Na carta escrita pela irmã da vítima, consta que o médico que atendeu Damião não o fez de modo adequado, tendo sido grosseiro com sua mãe:

[...] ela foi procurar o médico dele, que até o momento não havia lhe dado assistência. Aflita e chorando (reação normal de uma mãe, neste caso) fez reclamações ao Dr. 
O profissional acumulava a função de médico do hospital psiquiátrico e legista da polícia na cidade, algo que colocava suspeitas sobre seu laudo.

Dessa maneira, há versōes divergentes acerca da morte dependendo do documento que se leva em consideração. De um lado, o depoimento da mãe da vítima, amplamente divulgado através da carta escrita pela irmã e compondo a apuração dos "fatos" em dois processos judiciais, um de âmbito local e outro internacional, apontando para uma morte devido a maus-tratos e tortura; de outro, dois laudos realizados por médicos, compondo a perícia do "corpo" nesses mesmos processos, apontando para uma morte por causa natural ou indeterminada. De um lado, o saber jurídico e a "apuração dos fatos"; de outro, o saber médico e a "vistoria do corpo".

Não só esses documentos, mas também muitas das próprias investigaçōes científicas acerca do caso Damião Ximenes o descrevem como uma morte devida a maus-tratos e tortura. Friedrich (2006, p. 19) afirma que os sangramentos, escoriaçôes e hematomas da vítima foram "[...] decorrentes de briga com os enfermeiros da Clínica”, e Seixas e Nagado (2009, p. 305) se referem ao caso como aquele no qual o Estado brasileiro foi condenado "[...] por responsabilidade nos maus-tratos sofridos pela vítima [...]”. Andrade (2006, p. 159) descreve que "Damião [...] foi torturado e morreu na Clínica [...]”, e Lira e Dias (2010, p. 43) designam de "morte violenta" a de Damião dentro de uma "instituição de saúde mental". Alguns autores configuram a morte até mesmo como assassinato e homicídio: Calavarro e Brewer (2008, p. 93) falam do caso Ximenes Lopes como aquele no qual "um homicídio" ocorreu dentro de uma "clínica psiquiátrica”; Borges (2009, p. 27), no item "O Caso", afirma que Damião teria sido "assassinado" na casa de repouso.

De certo modo, esses autores parecem se basear em grande parte nos "fatos provados", segundo a sentença da Corte IDH, para realizar suas considerações sobre o caso, ou seja, no saber jurídico sobre o caso, e não tanto no saber médico sobre o corpo: teria ocorrido uma morte por maus-tratos. O conteúdo da carta escrita pela irmã da vítima também parece inspirar, ainda que em menor grau, essas análises científicas do caso: um homicídio.

Do mesmo modo como há convergências e divergências sobre a causa da morte da vítima, também há incertezas. Um relatório de sindicância da Casa de 
Repouso Guararapes foi realizado pela Secretaria de Saúde e Assistência Social de Sobral (SAAS) em 18 de fevereiro de 2000 (BRASIL, 2000). O relatório se pronunciou principalmente sobre a qualidade da assistência do "nosocômio" e recomendou seu descredenciamento (BRASIL, 2000, p. 5; 22), que aconteceu somente em julho de 2000, 9 meses após a morte da vítima. A equipe de auditores investigou os registros em prontuários, observou o cotidiano do estabelecimento médico e entrevistou os profissionais, afirmando que "não há elementos médicolegais para concluir-se que o óbito deveu-se a evento delituoso [...] embora não se possa excluir com absoluta segurança a possibilidade de que ele tenha ocorrido." (BRASIL, 2000, p. 8). No entanto, o relatório sugere que houve "má assistência ao paciente" e "atesta que houve ocorrência de maus tratos" por parte da equipe do estabelecimento junto a outros pacientes, bem como "abuso sexual" (BRASIL, 2000 , p. 8;13). A investigação ultrapassou o exame cadavérico, e ainda assim foi difícil afirmar com segurança que a morte se deu por maus-tratos: considera-se a hipótese de "queda do banheiro", "queda do leito" e "brigas com outros pacientes" como causa dos traumatismos apresentados pela vítima (BRASIL, 2000, p. 7-8).

Esses contrastes entre as informaçóes contidas nos documentos citados apontam para a dificuldade de descrever o caso Damião Ximenes e estabelecer quem é a vítima e quem é o algoz. Não se trata aqui de afirmar que a morte ocorreu em função de maus-tratos, consolidando a versão presente na sentença da Corte IDH e o saber jurídico. Também não é o caso de fazer o oposto, validando o saber médico e a versão dos médicos-legistas, ou mesmo apostar na perspectiva dos sanitaristas que conduziram a sindicância na casa de repouso. Se destaco as convergências e divergências entre as versões da morte, sublinhando mais as incertezas do que as certezas sobre o caso, é para que se possa apreendê-lo em outros termos, menos colados aos saberes hegemônicos sobre o assunto, sejam médicos ou jurídicos.

\section{A construção social da vítima}

Para que o Brasil viesse a ser condenado em um tribunal internacional, o Estado brasileiro foi considerado o algoz, em vez dos funcionários da casa de repouso acusados de espancar Damião Ximenes, do dono do estabelecimento considerado em precárias condiçõoes de funcionamento, ou do médico que atendeu a vítima no dia de sua morte. Uma das condições para que o Estado brasileiro fosse 
Ximenes Lopes ter sido considerado uma vítima, contrapondo os relatos segundo os quais ele teria se envolvido em brigas com outros pacientes (BRASIL, 2000) e "agitado dentro do carro" antes da penúltima internação (PEREIRA, 2001).

Procuro, neste tópico, apresentar justamente essa construção social da vítima no caso Damião Ximenes, exibindo as "lógicas classificatórias" (SARTI, 2009, p.94) que o visibilizam como "vulnerável" e não "perigoso", "deficiente mental" e não "doente mental".

A vítima aparece nas matérias da BBC e do DN como um "cearense". No primeiro jornal, uma "pessoa portadora de deficiência mental", um "paciente" da "clínica", incluído entre os "pacientes psiquiátricos"; no segundo, um "portador de transtornos mentais". Um dos participantes de órgãos governamentais de proteção aos direitos humanos, durante uma entrevista dada a mim, referia-se à vítima como "deficiente mental", com convicção e sem surpreender-se com a expressão. Enquanto me contava da coragem e da persistência da irmã de Damião em realizar a denúncia e comparecer aos eventos promovidos pelos organismos de proteção aos direitos humanos, e após eu lhe perguntar "O que contou para o desfecho, a condenação?", disse: "Foi principalmente a garra dela [irmã de Damião] em seguir em frente nessa luta e fazer justiça ao irmão deficiente mental [...]”.

Considerar Damiāo Ximenes portador de deficiência mental, e não de transtorno, está em convergência com a sentença da Corte IDH. A terminologia está presente tanto na introdução da causa quanto no momento da condenação:

Em consideração aos diferentes aspectos do dano aduzidos pela Comissão e pelos representantes, a Corte considera os seguintes aspectos: a) no que se refere ao senhor Damiāo Ximenes Lopes, este Tribunal leva em conta para a determinação da indenização a título de dano imaterial que está provado que este não recebeu assistência médica nem tratamento adequados como paciente portador de deficiência mental, que por sua condição era especialmente vulnerável e foi submetido a tratamentos cruéis, desumanos e degradantes enquanto esteve hospitalizado na Casa de Repouso Guararapes, situação que se viu agravada com sua morte (par. 112.7, 112.8, 112.9, 112.11, 112.12, 112.56 e 112.57 supra) (CORTE IDH, Sentença, 2006, p. 2; 87, grifo meu).

Se Damião fosse considerado pela Corte IDH como portador de transtorno, e não de deficiência mental, ela estaria em convergência com a Lei 10.216/2001, que diz respeito a "pessoas portadoras de transtornos mentais". Entretanto, Damião foi classificado como deficiente, e não doente, na sentença da Corte IDH, por conta de uma perícia, não médica, mas de um especialista em proteção 
dos direitos humanos de pessoas com deficiência. Esse perito destacou muito mais a situação de confinamento em que a vítima se encontrava e a vulnerabilidade que implica tal circunstância, ou seja, enfatizou a necessidade de proteção mais do que de tratamento:

As práticas hostis de violação dos direitos humanos das pessoas portadoras de deficiência mental seguem modelos similares em todo o mundo, o que abrange pessoas com diagnósticos de doença mental, tal como psicose, bem como pessoas portadoras de deficiência intelectual, e retardamento. Embora as necessidades das pessoas portadoras de doença mental e das pessoas portadoras de deficiência intelectual sejam muito diferentes, essas populações são frequentemente confundidas, amontoadas juntas em instituições e submetidas a muitas das mesmas formas de estigma e discriminação. (CORTE IDH, Depoimentos, Perito, 2005, p. 3, grifo meu)

Além disso, a categorização da vítima como portador de deficiência, e não transtorno, facilitou que a legislação internacional vigente pudesse ser aplicada ao caso:

Apesar da falta de uma linguagem específica sobre as pessoas portadoras de deficiência ou desordens mentais na Convenção Americana e em outros tratados gerais de direitos humanos, reconheceu-se amplamente que as pessoas portadoras de deficiência mental são protegidas pelas principais convençôes internacionais de direitos humanos que protegem todos os demais indivíduos (CORTE IDH, Depoimentos, Perito, 2005, p. 6)

Do mesmo modo como o saber biomédico não foi mais relevante que o saber jurídico para formular uma versão hegemônica do caso - os "fatos provados" da sentença da Corte IDH com base na declaração da mãe da vítima tendo se sobreposto aos laudos de causa da morte dos médicos peritos -, não foi a perspectiva psiquiátrica sobre o tratamento dos mental disorders que prevaleceu sobre a perspectiva dos direitos humanos sobre a proteção das disabilities.

$\mathrm{Na}$ carta da irmã da vítima, Damião é apresentado como parte de uma família de sete irmãos e gêmeo de um deles - Cosme e Damião (PEREIRA, 2001, p. 120). Damião teve "[...] vida normal até os 17 anos", mas após uma série de "fatores que podem ter contribuído para a doença de Damião" - nas próprias palavras da irmã de Damião, "a separação de Cosme e Damião", "uma pancada forte na cabeça", "depressão" e "gravidez difícil" - ele "falava coisas sem nexo" (PEREIRA, 2001, p. 123-125), apresentando "crises" e ficando "doente" (PEREIRA, 2001, p. 126). Ainda segundo a carta, a mãe de Damião começou a interná-lo na Casa de Repouso Guararapes em 1995, a segunda internação tendo sido em 1998 e a última - quando aconteceu sua morte -, em 1999. Depois da primeira internação, 
disse do hospital psiquiátrico que “[...] era só violência”. A segunda internação aconteceu após uma noite na qual Damião voltava de uma consulta psiquiátrica em Fortaleza e "agitou dentro do carro" (PEREIRA, 2001, p. 126), tendo sido levado pela polícia ao hospital. A irmã de Damião o descreve como tendo ficado "doente" após a "pancada" na cabeça dada pelo seu pai e a "gravidez difícil” vivida pela mãe já citadas. Ela também ressalta o relato dele de ter sofrido "violência" durante a internação psiquiátrica, ou seja, apresenta Damião como alguém que sofre uma ação de outrem, o que colabora para dissolver um dos principais estigmas da loucura: a periculosidade. $\mathrm{Na}$ "carta", ela conclui essa construção do irmão como vítima de parentes e profissionais de modo categórico. Diz que Damião recusouse a "tomar os remédios" e "[f]icou sem dormir, sem se alimentar, inquieto, mas não estava agressivo." (PEREIRA, 2001, p. 131, grifo meu).

Considerado uma vítima de circunstâncias domésticas promovidas pelos seus parentes - a causa da doença - e de circunstâncias institucionais promovidas pelos profissionais de Guararapes - a causa da morte -, Damião não podia ser rotulado como "perigoso", algo relevante para a mobilização coletiva no âmbito da luta antimanicomial nacional que antecedeu o julgamento do caso na Corte IDH, quando a vítima foi apontada como "deficiente", e não "doente", vulnerável e necessitado de proteção mais do que um indivíduo com transtornos mentais precisando de tratamento.

\section{Considerações finais}

A emergência do Núcleo Brasileiro de Direitos Humanos e Saúde Mental em 2006, bem como a proliferação de outros espaços de fiscalização de denúncias de violência nos estabelecimentos asilares após a condenação do Brasil por violação de direitos humanos, aponta para algo que atravessou a descrição e análise do caso Damião Ximenes: a proliferação da atividade pericial no campo da Saúde Mental, um contraponto ao debate mais frequente sobre a clínica até então. A multiplicação de espaços de fiscalização de denúncias de maus-tratos pode, ao contrário do que se busca com a criação dos mesmos, fomentar mais o teor pericial da atuação governamental do que o clínico, estimulando a realização de "pareceres", "auditorias" e "intervençôes" sobre estabelecimentos, ainda que com o intuito de produzir condiçôes para a futura garantia de acolhimento e acompanhamento dos internos. 
Os tratados internacionais que dizem respeito às pessoas com deficiência englobam aqueles que se referem a portadores de transtorno mental nesse terreno contemporâneo da articulação entre saúde mental e direitos humanos (DUDLEY; SILOVE; GALÉ, 2012, p. VII), a condição de vulnerabilidade e a necessidade de proteção destacando-se nesse cenário, de modo que a questão do confinamento e da violência ganha relevo. Anteriormente, no contexto da formulação do primeiro tratado internacional sobre o assunto pela Organização das Nações Unidas (ONU), uma resolução sobre os Princípios para a Proteção de Pessoas Acometidas de Problemas Mentais em 1991, a questão do abuso da psiquiatria para fins de controle de dissidentes políticos é que estava em jogo (BERTOLOTE, 1995, p. 153), ou seja, os desvios da prática psiquiátrica é que parecem ter motivado uma preocupação com os direitos humanos de pessoas internadas estabelecimentos asilares.

A intensificação da fiscalização dos hospitais psiquiátricos e o aumento dos canais de denúncia de violências nessas instituições podem, portanto, ampliar ainda mais esse debate acerca da privação de liberdade no campo da Saúde Mental, em um momento no qual se busca justamente o contrário: sublinhar a articulação entre saúde mental e atenção básica nos serviços extra-hospitalares, bem como as potencialidades das parcerias e redes no território (PITTA, 2011). Desse modo, podemos ter que conversar mais sobre perícias do que sobre clínicas no contexto atual do processo de reforma psiquiátrica brasileiro, bem como mais sobre confinamento asilar do que acerca de convivência no espaço urbano.

\section{Referências}

AMARANTE, P. Loucos pela vida: a trajetória da reforma psiquiátrica no Brasil. Rio de Janeiro: Fiocruz, 1995.

ANDRADE, I. A execução das sentenças da corte interamericana de direitos humanos. Revista Brasileira de Direito Internacional. Curitiba, v.3, n.3, p.148-162, 2006.

BERTOLOTE, J. Legislação relativa à saúde mental: revisão de algumas experiências internacionais. Revista de Saúde Pública. São Paulo, v. 29, n. 2, p. 152-156, 1995.

BORGES, N. Damiāo Ximenes: a primeira condenação do Brasil na Corte Interamericana de Direitos Humanos. Rio de Janeiro: Revan, 2009.

BRASIL. Secretaria Municipal de Saúde e Ação Social de Sobral. Relatório de sindicância referente ao processo 002 / 99. Sobral: Secretaria Municipal de Saúde e Ação Social, 2000. 
BRASIL. Secretaria Especial de Direitos Humanos da Presidência da República. SEDH cumpre decisão da OEA e indeniza familiares de Damião Ximenes. 15 de agosto de 2007. Disponível em: <http://www.mosap.org.br/docs/a529a.htm>. Acessado em: 23 jul 2010.

BRASIL. Estado do Ceará. Poder Judiciário. Comarca de Sobral. Juízo de Direito da $3^{a}$ Vara. Ação Penal 674/00. 4 volumes. Fortaleza, 2009.

CALAVARRO, J.; BREWER, S. O papel da litigância para a justiça social no sistema interamericano. SUR - Revista Internacional de Direitos Humanos, ano 5, n. 8, p. 85-99, jun 2008.

CARRARA, S. Crime e loucura: o surgimento do manicômio judiciário na passagem do século. Rio de Janeiro: Eduerj, 1998.

CASO Damião Ximenes: Brasil é condenado por corte internacional. Diário do Nordeste, Fortaleza (CE), 19 de agosto de 2006. Disponível em: <http://diariodonordeste.globo.com/ materia.asp? codigo=360644>. Acesso em: 7 dez 2012.

CASTEL, R. Os médicos e os juízes. In: FOUCAULT, M. (coord.). Eu, Pierre Rivière, que degolei minha mãe, minha irmã e meu irmão... um caso de parricídio no século XIX. Rio de Janeiro: Graal, 2000. p. 259-275.

CORREIA, L. Responsabilidade internacional por violação de direitos humanos: o Brasil e o caso Damião Ximenes.Prim@ Facie (UFPB), v. 7, p. 79-94, 2006.

CORTE INTERAMERICANA DE DIREITOS HUMANOS. Depoimentos, Caso Damião Ximenes Lopes Vs. Brasil. 2005. Disponível em: <http://www.corteidh.or.cr/ expediente_caso.cfm?id_caso $=240>$. Acesso em: 10 nov 2012

CORTE INTERAMERICANA DE DIREITOS HUMANOS. Sentença de 4 de julho de 2006 (Mérito, Reparações e Custas), Caso Ximenes Lopes Vs. Brasil. 2006. Disponível em: http://www.corteidh.or.cr/docs/casos/articulos/seriec_149_por.pdf. Acesso em: 10 jan 2013. DELGADO, P. As razôes da tutela: psiquiatria, justiça e cidadania do louco no Brasil. Rio de Janeiro: Te Corá. 1992.

DELGADO, P. Saúde Mental e Direitos Humanos: 10 anos da Lei 10.216 / 2001. Arquivos Brasileiros de Psicologia. Rio de Janeiro, v. 63, n. 2, p. 114-121, 2011.

DOUGLAS, M. Pureza e perigo. São Paulo: Perspectiva, 1976.

DUDLEY, M.; SILOVE, D.; GALÉ, F. Mental health and human rights: vision, praxis and courage. Oxford: Oxford University Press, 2012.

DURKHEIM, E.; MAUSS, M. Algumas formas primitivas de classificação. In: MAUSS, M. Ensaios de sociologia. São Paulo: Perspectiva, 1981. p. 399-456.

FRIEDRICH, T. Sistema Interamericano de Proteção de Direitos Humanos: uma análise a partir do Caso Damião Ximenes. Revista Brasileira de Direito Internacional. Curitiba, v. 3, n. 3, p.18-29, 2006. 
HUNT, L. A invenção dos direitos humanos: uma história. São Paulo: Cia das Letras, 2009. LIRA, R.; DIAS, R. A Saúde Mental na Corte Interamericana de Direitos Humanos. Revista Jurídica Consulex, ano XIV, n. 320, p. 43-44, maio 2010. Disponível em: <http:// global.org.br/programas/a-saude-mental-na-corte-interamericana-de-direitos-humanos/> Acesso em: $14 \mathrm{dez} 2010$.

PEREIRA, M. Damião: um grito de socorro e solidão. In: OLIVEIRA SILVA, M. (org.) A Instituição Sinistra: mortes violentas em hospitais psiquiátricos no Brasil. Brasília: CFP, p.115-222. 2001

PITTA, A. Um balanço da reforma psiquiátrica brasileira: instituições, atores e políticas. Ciência e Saúde Coletiva. Rio de Janeiro, v. 16, n. 12, p. 4579-4589, dez 2011.

ROSATO, C.; CORREIA, L. Caso Damião Ximenes Lopes: mudanças e desafios após a primeira condenação do Brasil pela Corte Interamericana de Direitos Humanos. SUR Revista Internacional de Direitos Humanos, v. 8, n. 15, p. 93-113, dez 2011.

SARTI, C. Corpo, violência e saúde: a produção da vítima. Sexualidade, Saúde e Sociedade, n. 1, p. 89-103, 2009.

SEIXAS, R.; NAGADO, B. A atuação do Brasil no banco dos réus no Sistema Interamericano de Proteção aos Direitos Humanos. Revista Brasileira de Ciências Criminais, n. 76, p. 293 311, 2009.

TENÓRIO, F. A reforma psiquiátrica brasileira, da década de 1980 aos dias atuais: história e conceito. História, Ciências, Saúde - Manguinhos. Rio de Janeiro, v. 9, n. 1, p. 25-59. jan-abr 2002.

UCHÔA, P. Brasil é condenado por Corte Interamericana de Direitos Humanos, BBC Brasil, 18 de agosto de 2006. Disponível em: <http://www.bbc.co.uk/portuguese/reporterbbc/ story/2006/08/060814_brasilddhhpu.shtml>. Acesso em: 7 dez 2012. 


\section{Abstract}

A case about mental health and human rights: its versions and its victim

In the context of Brazil's first conviction for violation of human rights, the "Damiao Ximenes Case", we seek to understand its conditions of possibility, highlighting the several versions about the case and the social construction of one of its elements: the victim. An anthropological approach that emphasizes the social forms of classification is adopted, and media, government and scientific documents are the object of description and analysis. Legal and medical knowledge are mobilized to generate different versions about the death of the victim, the "fact-finding" overriding the "body inspection ", generating consensus on the cause of death by maltreatment. The classification of the victim as a person with "disability", and not "mental disorder", contributes to the condemnation, and the expertise becomes crucial to the outcome of the case.

> Key words: mental health; disability; human rights; violence; victim. 